\title{
The causes of burn wounds among adult patients treated at Pelonomi Tertiary Hospital, Bloemfontein
}

\author{
B Daffue, ${ }^{1}$ D Moolman, ${ }^{1}$ S Ferreira, ${ }^{1}$ L $\operatorname{Roos},{ }^{1}$ L Schoeman, ${ }^{1}$ SJA Smit, ${ }^{2}$ G Joubert ${ }^{3}$ \\ ${ }^{1}$ Undergraduate medical student, School of Medicine, Faculty of Health Sciences, University of the Free State, Bloemfontein, \\ South Africa \\ ${ }^{2}$ Department of Surgery, Faculty of Health Sciences, University of the Free State, Bloemfontein, South Africa \\ ${ }^{3}$ Department of Biostatistics, Faculty of Health Sciences, University of the Free State, Bloemfontein, South Africa
}

Corresponding author: Prof S Smit (Gnchsjas@ufs.ac.za)

\begin{abstract}
Background: Burn injuries account for approximately 180000 deaths per annum, mostly in low- and middle-income countries.

Aim: This study sought to determine the causes of burn wounds among adults admitted to the Burn Wound Unit at Pelonomi Tertiary Hospital in Bloemfontein for treatment.

Methods: This was a prospective, cross-sectional study. The target population consisted of adult patients, hospitalised for burn wounds at Pelonomi Tertiary Hospital in Bloemfontein, between July 2016 and early January 2017. Relevant data was collected by means of a structured interview using a questionnaire.

Results: A total of 49 patients were interviewed during the study period. Almost two-thirds of the patients were male $(65.3 \%, n=32)$. The median age was 33 years (range 18 to 64 years). In most cases, the injury occurred at home $(77.6 \%$, $n=38)$. Three quarters of the reported incidents $(77.6 \%, n=38)$ were considered accidental of which $68.4 \%(n=26)$ were related to domestic activities. At the time of the accidental incident, 39.5\% $(n=15)$ patients had consumed alcohol. Eleven $(22.4 \%)$ of the incidents were intentional with $63.6 \%(n=7)$ attributed to assault. The two main causes of burn injuries were flames including flaming liquids $(59.2 \%, n=29)$ and hot liquids $(22.5 \%, n=11)$. The most frequent area of injury was the left front thigh.

Conclusion: The predominant cause of burn wounds was flames including flaming liquids, and injuries were mostly accidental in nature. Alcohol consumption and domestic activities were common in accidental burns.
\end{abstract}

\section{Introduction}

Burn injuries account for approximately 180000 deaths per annum, of which most occurrences are in low- and middleincome countries. ${ }^{1}$ Research indicates that situations leading to burn wound injuries worldwide are mostly unintentional and occur at home, ${ }^{2,3}$ followed by work-related burns, most commonly in the food industry and factory production. ${ }^{3}$ Scalding and flames are the most common causes of burn injuries in developed as well as in developing countries..$^{3,4-7}$ This also holds true for South Africa. ${ }^{8-10}$ Causing intentional burn injuries to another person, as method of assault, was found to be uncommon in Western Australia with 25 patients hospitalised for assault burn injuries compared to 2209 who were hospitalised due to unintentional burn injuries during the study period 2004 to $2012 .{ }^{11}$ Fire-assisted suicide attempts have been reported in developed countries such as Taiwan, however, these attempts are reported to be more frequently seen in developing countries. ${ }^{3,9}$ Allorto et al. found that patients at a South African regional hospital who attempted suicide by fire were females, aged between 21 and 32 years. ${ }^{9}$

Risk factors for overall mortality in burn patients documented in the Netherlands included age (mostly the elderly and children) and the total body surface area (TBSA) affected. ${ }^{12}$ Allorto et al. state that predisposing health conditions such as epilepsy are a major risk for acquiring burn wound injuries. ${ }^{9}$

Some research indicates a higher number of men hospitalised due to burn wounds, ${ }^{7,812-14}$ whereas the WHO indicates that women have a marginally higher mortality rate compared to men. ${ }^{1}$ However, it is pointed out that women are at a higher risk of being victims of assault that results in burn wounds. ${ }^{11}$ The age of the largest portion of adult patients range from 25-54 years in Nepal ${ }^{6}$ to $35-44$ years in Taiwan. ${ }^{3}$ Studies showed that patients with burn injuries in developed countries 
tended to have a high level of education, ${ }^{3}$ while the level of education of patients in developing countries was low. ${ }^{5}$ Research done in the Netherlands ${ }^{12}$ and Australia ${ }^{14}$ showed a rise in incidence of burn wounds in the lower income class and a decrease in incidence in the middle- and high-income classes.

Allorto et al. reported an average of 23\% TBSA burnt in the 247 adult patients admitted to a regional hospital in South Africa. ${ }^{9}$ This correlates with studies done in Taiwan $(19 \%),{ }^{3}$ Ecuador $(11-20 \%),{ }^{7}$ Catalonia $(16 \%)^{4}$ and Singapore $(13.5 \%) .{ }^{13}$ Countries such as the Netherlands and Australia documented an average TBSA of less than $10 \% .^{12,14}$ The regions of the body that are most at risk for burn injuries are the upper limbs as well as the face and chest. ${ }^{5,9}$

To our knowledge, no studies regarding the causes of burn wounds in adults have been done in the Free State Province, thus we saw the need for such a study to be conducted at the Burn Wound Unit of Pelonomi Tertiary Hospital in Bloemfontein. This Unit has 23 beds (of the 720 beds in the hospital) and serves not only the Free State, but the entire central part of South Africa. The clinical impression was that the majority of burn injuries in central South Africa are related to impoverished household circumstances.

\section{Aim and objectives}

The aim of this study was to determine the causes of burn wounds among adults admitted to the Burn Wound Unit at Pelonomi Tertiary Hospital in Bloemfontein for treatment.

Secondary objectives were to determine (i) the demographic profile of the patients, (ii) the severity of the burn wounds, and (iii) the association between the causes and the demographic profile as well as between the causes and the severity of the burn wounds.

\section{Methods}

\section{Study design and sample}

This was a prospective, cross-sectional study. The target population consisted of adult patients hospitalised for burn wounds at Pelonomi Tertiary Hospital in Bloemfontein, between July 2016 and early January 2017.

Patients who were included in the study were 18 years or older who were willing to respond to the questionnaire in Afrikaans, English or Sesotho. Patients who were unwilling or unable to participate were excluded. The sample would have consisted of the first 100 individuals seeking treatment, but only 49 of the 76 patients admitted during the study period were available for interviewing at the times the researchers visited the hospital.

\section{Measurement}

The data was collected by means of a structured interview using a questionnaire designed by the researchers according to the objectives. One or more of the student researchers visited the Burn Wound Unit on a weekly basis during the study period to collect data.

Demographic information captured included date of admission, age, gender, marital status, level of education, occupation, monthly income and presence of epilepsy or mental illness. Questions related to the patients' burn wounds included whether this was the patient's first burnrelated injury, place and cause of the injury, date that the patient sought medical attention and method of transport to the hospital. Patients had to indicate whether the injury was accidental or intentional. For accidental injuries, the cause thereof and any substance use were recorded. Where the injury was intentional, patients had to provide the cause, relationship to the alleged assailant and whether legal action was taken.

Severity was determined by the TBSA, where the researchers looked at where the injuries occurred on the body and compared it to a "rule of nine" diagram (which is the standard of measuring TBSA in the clinical area). ${ }^{15}$ With the regions affected, we assigned each body part a number and then calculated the most prevalent regions.

\section{Pilot study}

The pilot study consisted of 10 consecutive patients admitted to the Burn Wound Unit at Pelonomi Tertiary Hospital in July 2016. After the pilot study, no changes were made to the questionnaire. Patients from the pilot study were included in the main study due to the lower than anticipated number of patients seeking medical attention for burn wounds during the study period.

\section{Data analysis}

Data from the questionnaires were entered into an Excel spreadsheet. Data analysis was performed by the Department of Biostatistics, Faculty of Health Sciences, University of the Free State (UFS). Results were summarised by frequencies and percentages (categorical variables) and medians (numerical variables).

\section{Ethical aspects}

The study was approved by the Health Sciences Research Ethics Committee (HSREC), UFS [HSREC-S 21/2016]. Permission to conduct the study was given by the Free State Department of Health. Data was handled confidentially and no identifying information was captured on the questionnaire.

\section{Results}

A total of 49 patients of the 76 adult admissions (out of a total of 130 admissions) from July to December 2016 were interviewed. The median time between hospital admission and conducting the interview with the patient was four days (range 0 to 24 days). Almost two-thirds of the patients were male $(65.3 \%, n=32)$. The highest percentage of patients was single $(38.8 \%, n=19)$ while $30.6 \%(n=15)$ were married and $16.3 \%$ $(n=8)$ lived with a partner. Almost half $(46.9 \%, n=23)$ indicated that they were unemployed at the time of the incident.

As shown in Table 1, 53.0\% of the patients were in the age range 31 to 50 years. The median age was 33 years (range 18 to 64 years). Half of the patients $(51.0 \%)$ had attended secondary school but did not complete Grade 12 while $20.4 \%$ had obtained matric. Most of the patients (73.5\%) reported a monthly income of R2 000 or less. During the study period, 
the highest percentages of patient admissions for burn wounds were for July (26.5\%), December (24.5\%) and September $(22.5 \%)$.

Table 1. Demographic information of participants $(n=49)$

\begin{tabular}{|c|c|}
\hline Variable & $n(\%)$ \\
\hline \multicolumn{2}{|l|}{ Age range (years) } \\
\hline$\leq 20$ & $5(10.2)$ \\
\hline $21-30$ & $12(24.5)$ \\
\hline $31-40$ & $13(26.5)$ \\
\hline $41-50$ & $13(26.5)$ \\
\hline $51-60$ & $5(10.2)$ \\
\hline$\geq 61$ & $1(2.0)$ \\
\hline \multicolumn{2}{|l|}{ Highest level of education } \\
\hline None & $4(8.2)$ \\
\hline Primary school & $9(18.4)$ \\
\hline Secondary school (excluding Grade 12) & $25(51.0)$ \\
\hline Grade 12 & $10(20.4)$ \\
\hline Diploma & $1(2.0)$ \\
\hline \multicolumn{2}{|l|}{ Monthly income range } \\
\hline$<\mathrm{R} 1000$ & $27(55.1)$ \\
\hline R1 001-R2 000 & $9(18.4)$ \\
\hline R2 001-R5 000 & $7(14.3)$ \\
\hline R5 001-R10 000 & $4(8.2)$ \\
\hline R10 001-R20 000 & $1(2.0)$ \\
\hline R20 001-R50 000 & $1(2.0)$ \\
\hline \multicolumn{2}{|c|}{ Month of admission due to burn wounds (2016) } \\
\hline July & $13(26.5)$ \\
\hline August & $6(12.2)$ \\
\hline September & $11(22.5)$ \\
\hline October & $5(10.2)$ \\
\hline November & $2(4.1)$ \\
\hline December & $12(24.5)$ \\
\hline
\end{tabular}

Most of the patients $(87.8 \%, n=43)$ indicated that this was their first burn-related injury. While $10.2 \%(n=5)$ reported suffering from epilepsy or other condition that causes convulsions, and $4.1 \%(n=2)$ from mental illness e.g. depression, $85.7 \%(n=42)$ reported no history of these conditions.

Most patients $(69.3 \%, n=34)$ immediately sought medical attention after the injury occurred while $20.4 \%(n=10)$ waited a day. Two patients $(4.1 \%)$ waited between four to seven days. More than half of the patients $(53.1 \%, n=26)$ were transported to hospital via an ambulance and $32.7 \%(n=16)$ were taken to hospital by car. Six patients $(12.2 \%)$ came by public transport.

In most cases, the injury occurred at home $(77.6 \%, n=38)$ while $6.1 \%(n=3)$ occurred at work and $16.3 \%(n=8)$ at other locations, such as a public place $(10.2 \%, n=5)$, friend's house $(4.1 \%, n=2)$ and recreational area $(2.0 \%, n=1)$.

Three-quarters of the reported incidents $(77.6 \%, n=38)$ were considered accidental while $22.4 \%(n=11)$ were intentional. Overall causes as well as the causes of the accidental or intentional injury are summarised in Table 2. The two main causes of burn injuries were flames including flaming liquids $(59.2 \%)$ and hot liquids (22.5\%). In July, the main cause was flames $(61.5 \%)$ whereas in December the main cause was flaming liquids (41.7\%).

\begin{tabular}{lc} 
Table 2. Overall cause of burn wounds as well as cause of \\
accidental and intentional injuries \\
\hline Variable & $n(\%)$ \\
\hline $\begin{array}{l}\text { Overall cause of injuries ( } \boldsymbol{n}=\mathbf{4 9 )} \\
\text { Flames }\end{array}$ & $19(38.8)$ \\
Hot liquids (e.g. water, oil, porridge) & $11(22.5)$ \\
Flaming liquids (e.g. burning petrol, Molotov & $10(20.4)$ \\
cocktail) & \\
Corrosive chemicals (e.g. sulphuric acid, household & $2(4.1)$ \\
chemicals) & \\
Contact burns (e.g. stovetop, oven, warm dish, hot & $7(14.3)$ \\
pipes) & \\
Cause of injuries: accidental ( $\boldsymbol{n}=\mathbf{3 8})$ & \\
Domestic activities (cooking or cleaning) & $26(68.4)$ \\
Occupational hazard & $2(5.3)$ \\
$\begin{array}{l}\text { Destruction of property (e.g. burning building) } \\
\text { Open fire (e.g. veld fire, barbeque.) }\end{array}$ & $3(7.9)$ \\
Other & $2(5.3)$ \\
Cause of injuries: intentional ( $\boldsymbol{n}=\mathbf{1 1})$ & $5(13.2)$ \\
Assault & \\
Self-inflicted for reasons other than suicide & $7(63.6)$ \\
Practical joke (prank) & $1(9.1)$ \\
Other & $2(18.2)$ \\
& $1(9.1)$
\end{tabular}

Most of the 38 accidental injuries were related to domestic activities (68.4\%). Other causes $(13.2 \%)$ included recreational accidents $(5.3 \%, n=2)$, a corrosive chemical found in open area $(2.6 \%, n=1)$ and unspecified $(5.3 \%, n=2)$. No incidents of burns caused by severe sunburn, lightning, radiation, friction or electricity were reported.

Two $(5.3 \%)$ of the patients indicated that they were injured during an epileptic seizure. At the time of the accidental incident, $39.5 \%(n=15)$ had consumed alcohol and 7.9\% $(n=3)$ stated that they were under the influence of illicit drugs.

As shown in Table 2, more than $60 \%$ of the 11 intentional injuries were attributed to assault (63.6\%) followed by practical jokes $(18.2 \%)$. For the 10 cases where there was an assailant, the assailant was a family member $(n=3)$, spouse $(n=2)$, stranger $(n=2)$, a neighbour $(n=1)$, a partner $(n=1)$ or an acquaintance $(n=1)$. Half of the 10 patients did not pursue legal action, three indicated that legal steps would still be taken, in one case the whereabouts of the assailant was not known, and in one case, the assailant was arrested.

The median affected TBSA was $10.2 \%$ (range 0.3 to $58.2 \%$ ). Four patients had a TBSA higher than $40.0 \%$. Patients with accidental injuries had a median of $7.4 \%$ TBSA affected and patients with intentional injuries a median of $22.2 \%$. 

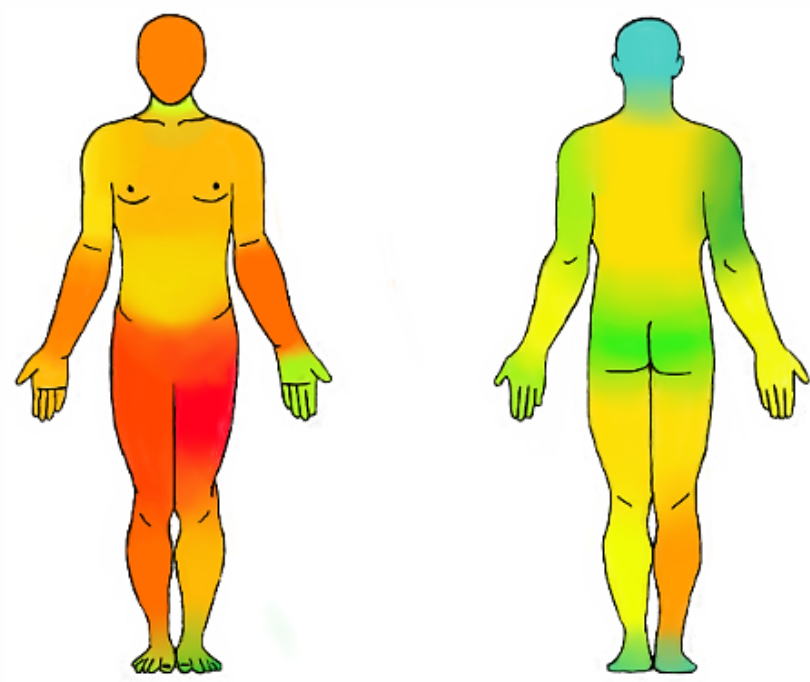

Highest

\section{Lowest}

\section{Figure 1. Burnt regions on body}

Figure 1 shows the regions where patients were most frequently burnt. The most frequent area of injury was the left front thigh (38.8\% of patients) while the back of the head was rarely affected ( $4.1 \%$ of patients). Other areas affected for $25 \%$ or more of patients were the face $(30.6 \%)$, left front upper arm (26.5\%), right front lower arm (28.6\%), left front lower arm $(30.6 \%)$, right front thigh $(32.7 \%)$, right front lower leg $(30.6 \%)$ and right back lower leg $(26.5 \%)$.

The highest median age of 44 years was for patients with contact burns. Flaming liquids resulted in the highest median of affected TBSA (16.9\%) while corrosive chemicals had the lowest median of affected TBSA at $0.7 \%$. Males were more likely to be burned with flames and hot liquids than females. Employed patients' injuries were more likely due to contact burns or hot liquids and unemployed patients' injuries due to flaming liquids.

\section{Discussion}

The number of patients interviewed in July and December were approximately the same. Burn wounds are commonly associated with winter and the largest percentage of cases admitted in July was due to flames. Festive activities in December may have contributed to this month's number. The extended time lapse between hospital admission and the interview is due to absence of the specific patients in the Burn Unit at time of interviewing. This absence can be explained by patients being treated in theatre during student visits. One instance of a patient who was unable to communicate due to a tracheotomy tube led to the postponing of interviewing until the tube had been removed. Lack of patient cooperation did not lead to invalid or missing data as was expected. One patient was identified to have been interviewed twice and the duplicate entry was excluded from the results. The language barrier did not play a role during interviews with patients. On occasions where patients were not deemed "compos mentis" the interview was postponed until a later occasion.

The number of total admissions in the study period $(n=130)$ are similar to those of preceding years for the months July to December: 137 in 2014 and 161 in 2015. In 2017, the total admissions were 151 for July to December.

This study found that $10.2 \%$ of the patients had epilepsy of which two reported experiencing a seizure when they were burnt. Allorto et al. reported that epilepsy was a major risk factor for sustaining burn wounds with $50 \%$ of the adult patients in their study reported to have epilepsy. ${ }^{9}$

Most burns wounds were accidental incidents and occurred at the patient's home, which is similar to results seen in other studies. ${ }^{2,3}$ However, the second most common place where injuries occurred was at locations such as a public or recreational area or a friend's house, and not at work as noted in the literature. ${ }^{3}$ The reason for this could be the high unemployment rate among the patients in this study.

Flames including flaming liquids were the most common causes of burns. This correlates with similar studies done in South Africa ${ }^{8-10}$ and other parts of the world. ${ }^{3,4-7}$

Table 3. Age, total body surface area affected, gender and employment status by cause of burn wounds $(n=49)$

\begin{tabular}{|c|c|c|c|c|c|}
\hline \multirow[b]{2}{*}{ Variable } & \multicolumn{5}{|c|}{ Main causes of injuries } \\
\hline & $\begin{array}{c}\text { Flame } \\
n=19\end{array}$ & $\begin{array}{l}\text { Hot liquids } \\
\quad n=11\end{array}$ & $\begin{array}{c}\text { Flaming liquids } \\
n=10\end{array}$ & $\begin{array}{c}\text { Corrosive } \\
\text { chemical } n=2\end{array}$ & $\begin{array}{c}\text { Contact burns } \\
n=7\end{array}$ \\
\hline Median age (years) & 38 & 32 & 32.5 & 18 & 44 \\
\hline Median TBSA affected (\%) & 11.0 & 14.0 & 16.9 & 0.7 & 2.9 \\
\hline Gender & $\mathrm{n}(\%)$ & $\mathrm{n}(\%)$ & $\mathrm{n}(\%)$ & $\mathrm{n}(\%)$ & $\mathrm{n}(\%)$ \\
\hline Male $(n=32)$ & $15(79.0)$ & $8(72.7)$ & $6(60.0)$ & $0(0)$ & $3(42.9)$ \\
\hline Female $(n=17)$ & $4(21.0)$ & $3(27.3)$ & $4(40.0)$ & $2(100.0)$ & $4(57.1)$ \\
\hline \multicolumn{6}{|l|}{ Employment status } \\
\hline Employed $(n=26)$ & $10(52.6)$ & $7(63.6)$ & $4(40.0)$ & $0(0)$ & $5(71.4)$ \\
\hline Unemployed $(n=23)$ & $9(47.4)$ & $4(36.4)$ & $6(60.0)$ & $2(100.0)$ & $2(28.6)$ \\
\hline
\end{tabular}


Alcohol consumption was common among accidental cases. Some patients were burned due to dangerous behaviour; a direct consequence of their intoxication. Other patients were incapacitated by the effects of alcohol and could not save themselves from the flames. One patient reported that he passed out due to his drinking, and did not regain consciousness until he was completely immolated. In the US it was reported that substance abuse was more common in intentional than accidental cases, but we did not have the data to investigate this. ${ }^{16}$

Only one case of self-inflicted burn injuries was reported in this study by a female patient. Self-inflicted burns were much more common in another South African study ${ }^{9}$ as well as one done in Taiwan. ${ }^{3}$ Both these studies also indicated that selfinflicted burns were more common in females.

According to the $\mathrm{WHO},{ }^{1}$ burn-related injuries were equally prevalent in men and woman, however, in this study, most of the patients were men. Men were also found to suffer burn wounds more frequently than women did in various other studies. ${ }^{7,8,12-14}$ The median age of burn victims in this study is similar to studies done in Taiwan ${ }^{3}$ and Nepal. ${ }^{6}$

In developed countries, burn injuries were mainly workrelated and occurred in educated people. ${ }^{3}$ Most patients in this study, however, reported the broad cause of their accidents to be domestic activities. Nearly half the patients were unemployed and most had less than Grade 12 education, thus reflecting a low socio-economic status. The community survey results of 2016 indicated that the vast majority of Free State households $(94.0 \%)$ were connected to electricity. ${ }^{17}$ From the census of 2011, it was clear that many Free State households used electricity for cooking $(84.5 \%)$ or lighting $(89.9 \%)$, but a smaller percentage used electricity for heating $(55.7 \%) .{ }^{18}$ Of the cases in July, more than half were due to flames, possibly linked to heating.

The percentage TBSA affected in this study was marginally lower than reported in studies done in South Africa, ${ }^{8}$ Taiwan, ${ }^{3}$ Catalonia ${ }^{4}$ and Singapore, ${ }^{13}$ but slightly higher than the studies done in Netherlands ${ }^{12}$ and Australia. ${ }^{14}$

This study found that the most common area affected by burn wounds was the front part of the legs; particularly the upper thighs. Other studies suggested that the upper limbs, face and chest are generally affected. ${ }^{5,9}$

The highest median percentage affected TBSA was caused by flaming liquids, which can be expected as it was one of the most common modes of injury in assault (understandably because the intent of the assailant may have been to cause severe injuries)

\section{Study limitations}

Approximately two-thirds of adult patients admitted during this period were interviewed for this study. Student researchers visited the Unit weekly, and it is unclear to which extent the sample could be biased.

During data collection and analysis, it was found that the use of substances in the case of intentional burns should have been examined and included in the questionnaire. The use of more options in certain questions, such as place of injury, would have simplified data analysis. Employment status of participants indicated the state of employment at the time of the interview and did not include an option for intermittent employment.

The only measurement of severity was the percentage TBSA. The degree of the burns (i.e. first-, second- or thirddegree) was not included, as it was not noted in the patients' files and would have required more time and expertise to examine each individual burn wound on every patient.

Regarding the survival bias, it is possible that some incidents could have resulted in patient death, without the student researchers seeing these patients.

\section{Recommendations}

Awareness should be raised, especially about domestic activities, e.g. how to cook safely, handle boiling water and how to respond correctly in case of a fire (throwing sand on oil flames and not water), taking into account the apparently common use of open flames in households. The general population also needs to be educated from an earlier age, e.g. schools need to emphasise the dangers of burns in prevention of burn wounds in later life.

Alcohol consumption was a common factor and awareness of burn wound incidents while under the influence should be raised; especially aimed towards other family members so they can prevent an incident from occurring.

Most patients who were assaulted by family members (including their spouse) did not take any legal action; even if it was an intentional severe injury. Therefore, we recommend that studies should consider the psychological profiles of burn patients who exhibit this behaviour. More information should be gathered about the victim's relationship with the assailant and why they are so hesitant to take legal action.

We recommend a similar study where the measure of severity includes the degree of burn wounds. In addition, the correlation between substance abuse and the patients' extent of injuries can be investigated.

\section{Conclusion}

The predominant cause of burn injuries in adult patients admitted to Pelonomi Tertiary Hospital for treatment was flames including flaming liquids. The injuries were mostly accidental and related to domestic activities. Regarding the demographics, patients tended to be male, unemployed with a low level of education. The left upper thigh was burnt most often. Although the median percentage TBSA affected was relatively low compared to another South African study, four patients had more than $40 \%$ TBSA affected.

\section{Acknowledgement}

The authors thank the nursing staff at the Pelonomi Tertiary Hospital's Burn Wound Unit for their welcoming attitude and for introducing us to all the patients each week; and Ms T. Mulder, medical editor, School of Medicine, UFS, for technical and editorial preparation of the manuscript. We thank the reviewers for their valuable constructive comments. 


\section{Conflict of interest}

None

\section{REFERENCES}

1. World Health Organization. Burns. Fact sheet. Geneva: World Health Organization, 2014 (updated August 2017, accessed 10 March 2016). Available from: http://www.who.int/mediacentre/ factsheets/fs365/en/.

2. Shrivastava PS, Shrivastava SR. An epidemiological study of adult female burns patients admitted in a tertiary care hospital. Prog Health Sci. 2012;2(2):21-8.

3. Chien WC, Pai L, Lin CC, Chen HC. Epidemiology of hospitalized burns patients in Taiwan. Burns 2003;29(6):5828. Available from: http://dx.doi.org/10.1016/S03054179(03)00133-5 PMID: 12927984

4. Barret JP, Gomez P, Solano I, Gonzalez-Dorrego M, Crisol FJ. Epidemiology and mortality of adult burns in Catalonia. Burns. 1999;25(4):325-9. Available from: http://dx.doi.org/10.1016/ S0305-4179(98)00190-9 PMID: 10431980

5. Ringo Y, Chilonga K. Burns at KCMC: epidemiology, presentation, management and treatment outcome. Burns. 2014;40(5):1024-9. Available from: https://doi.org/10.1016/j. burns.2013.10.019 PMID: 24280526

6. Gupta S, Mahmood U, Gurung S, et al. Burns in Nepal: a population based national assessment. Burns. 2015;41(5):112632. Available from: https://doi.org/10.1016/j.burns.2014.11.012 PMID: 25523087

7. Ortiz-Prado E, Armijos L, Iturralde AL. A population-based study of the epidemiology of acute adult burns in Ecuador from 2005 to 2014. Burns. 2015;41(3):582-9. Available from: https:// doi.org/10.1016/j.burns.2014.08.012 PMID: 25440845

8. Rode H, Rogers AD, Numanoglu A, et al. A review of primary and secondary burn services in the Western Cape, South Africa. S Afr Med J. 2015;105(10):853-7. Available from: http://dx.doi. org/10.7196/SAMJnew.8187 PMID: 26428592

9. Allorto NL, Oosthuizen GV, Clarke DL, Muckart DJ. The spectrum and outcome of burns at a regional hospital in South Africa. Burns. 2009;35(7):1004-8. Available from: http://dx.doi. org/10.1016/j.burns.2009.01.004 PMID: 19447554
10. den Hollander D, Albert M, Strand A, Hardcastle TC. Epidemiology and referral patterns of burns admitted to the Burns Centre at Inkosi Albert Luthuli Central Hospital, Durban. Burns. 2014;40(6):1201-8. Available from: https://doi. org/10.1016/j.burns.2013.12.018 PMID: 24439933

11. O'Halloran E, Duke J, Rea S, Wood F. In the media: burns as a method of assault. Burns. 2013;39(6):1311-5. Available from: https://doi.org/10.1016/j.burns.2013.03.004 PMID: 23618547

12. Dokter J, Vloemans AF, Beerthuizen GI, et al. Epidemiology and trends in severe burns in the Netherlands. Burns. 2014;40(7):1406-14. Available from: https://doi.org/10.1016/j. burns.2014.03.003 PMID: 24703338

13. Chong SJ, Song C, Tan TW, Kusumawijaja G, Chew KY. Multivariate analysis of burns patients in the Singapore General Hospital Burns Centre. Burns. 2009;35(2):215-20. Available from: https://doi.org/10.1016/j.burns.2008.06.014 PMID: 18950948

14. Duke J, Rea S, Semmens J, Wood F. Urban compared with rural and remote burn hospitalisations in Western Australia. Burns. 2012;38(4):591-8. Available from: https://doi.org/10.1016/j. burns.2011.10.015 PMID: 22103987

15. eMedicineHealth. Burn percentage in adults: Rule of nines. New York: MebMD, 2016 (accessed 06 November 2017). Available from: https://www.emedicinehealth.com/burn_percentage_in adults rule of nines/article em.htm

16. Kaufman $\mathrm{MS}$, Graham CC, Lezotte D, et al. Burns as a result of assault: associated risk factors, injury characteristics, and outcomes. J Burn Care Res. 2007;28(1):21-8; discussion 29. Available from: http://dx.doi.org/10.1097/ BCR.0B013E31802C896F PMID: 17211196

17. Statistics South Africa. Community Survey 2016. Provinces at a glance. Pretoria: Statistics South Africa, 2016 (accessed 14 January 2018). Available from: http://cs2016.statssa.gov.za/wpcontent/uploads/2016/06/CS-2016-Provinces-at-a-glance.pdf

18. Statistics South Africa. Census 2011. Provinces at a glance. Pretoria: Statistics South Africa, 2012 (accessed 14 January 2018). Available from: http://www.statssa.gov.za/census/ census_2011/census_products/Provinces $\% 20$ at $\% 20 a \% 20$ glance $\% 2016 \% 20$ Nov\%202012\%20corrected.pdf 